\title{
Depth Estimation and Source Location of Magnetic Anomalies from a Basement Complex Formation, Using Local Wavenumber Method
}

\author{
J. A. Olowofela, O. D. Akinyemi, B.S. Badmus, * M. O. Awoyemi, O. T. \\ Olurin and S. A. Ganiyu \\ Department of Physics, Federal University of Agriculture, Abeokuta, P.M.B 2240, Abeokuta, Ogun State. \\ Nigeria. \\ * Department of Physics, Obafemi Awolowo University, Nigeria.
}

\begin{abstract}
Source locations and depths to magnetic contacts were estimated from the total intensity magnetic field of an area of 3,025.25 square kilometres on geographical latitude $7^{\circ} 00^{\prime} N$ to $7^{\circ} 30^{\prime} \mathrm{N}$ and longitude $3^{\circ} 00^{\prime} E$ to $3^{\circ} 30^{\prime} E$ within Abeokuta area, using local wavenumber method. This study was carried out using digitised airborne magnetic data of basement complex formation. Structural interpretation of the magnetic data was achieved through applying advanced processing techniques that provide automatic delineation and depth estimation of the magnetic structures. Local wavenumber method was used for locating and estimating depth to magnetic contact. The magnetic contact depth ranges from $0.145 \mathrm{~km}$ to $2.692 \mathrm{~km}$.
\end{abstract}

Key words: Aeromagnetic, basement, magnetic intensity, magnetic inclination, magnetic declination, magnetic susceptibility

Submitted Date 25 June 2013

Accepted Date: 01 July 2013

\section{Introduction}

Aeromagnetic data have been widely used by petroleum industry after the World War II [1]. Aeromagnetic data records variation in the magnitude of the earth's magnetic field, in order to detect local changes in the properties of the underlying geology. In oil exploration, structure in oil-bearing sedimentary layers is controlled by topographic features (such as ridges or faults) on the basement surface which can be mapped using aeromagnetic data. Recent improvements in acquisition and processing technology enables better understanding of the subsurface structure and define the basin architecture. Magnetic data has a wide variety of applications in preliminary and detailed studies of geophysical structures such as magnetic sheets, contact and faults. In mineral exploration, the magnetic method can be used to determine the body parameters. However, interpretation of magnetic anomalies is complicated by factors such as; horizontal displacement between actual body locations, dipolar nature of magnetic anomalies, and asymmetric shape of magnetic anomalies due to inclined vector magnetization, asymmetric shape of magnetic anomalies relevant to non-vertical structures [2]. Numerous methods have been designed to eliminate one or more of the mentioned complexities. Reduction to Pole RTP removes the asymmetry caused by the non-vertical magnetization direction which would have been observed in a magnetic pole [3]. In addition to the RTP technique, the horizontal displacement between the acquired anomaly and causative body location can be removed by edge detection methods. The most important methods of edge detection are zero-crossing on a second vertical derivative or by maxima on the horizontal derivative and analytic signal. Among the edge detection methods, the analytic signal has a greater application because of its independency to the body magnetization such as inclination and declination, remanent magnetization and body dip. The superposition effect due to different adjacent bodies can restrict the analytic signal application. In this study 3-D quantitative interpretation method termed local wavenumber which works in the frequency domain and uses the phase variation of potential field data and its derivatives was used to analyse airborne magnetic data. Digitised aeromagnetic data (sheet 260) of Abeokuta as obtained by Nigerian Geological Survey Agency in 2009 were employed to determine the location and depth to the magnetic contact.

\subsection{Location of the Study Area}

The study was carried out in Abeokuta area of Ogun state, south western Nigeria. The area is located within

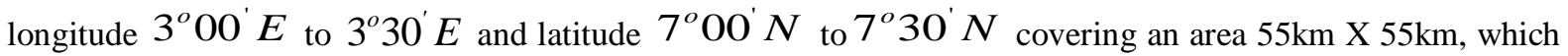
is 3,025 square kilometres. Ogun state is bounded in the west by Benin Republic, in the south by Lagos, in the 
north by Oyo/Osun and in the east by Ondo State. The location and total magnetic intensity maps of Abeokuta are shown in Fig. 1 and Fig. 2 respectively

\subsection{Geological Setting}

Abeokuta falls within the basement complex of the geological setting of south-western Nigeria (Fig. 1). The basement complex rocks of pre-cambrian age are made up of older and younger granites, with the younger and older sedimentary rocks of both tertiary and secondary ages. The area is underlain by basement rocks which cover about $40 \%$ of land mass in Nigeria [4].

\section{Materials}

Abeokuta area was covered by an aeromagnetic survey conducted by Nigeria Geological Survey Agency of Nigeria in 2009. The aeromagnetic data were obtained using a proton precession magnetometer with a resolution of $0.01 \mathrm{nT}$. The airborne geophysical work was carried out by Fugro Airborne Surveys Canada. Aeromagnetic survey was flown at $500 \mathrm{~m}$ flight line spacing and tie line spacing of $5000 \mathrm{~m}$. The flight line direction is in the direction $135^{\circ}$ azimuth, the tie line direction is $45^{\circ}$ azimuths. The sensor mean terrain clearance is $80 \mathrm{~m}$. The average magnetic inclination, declination and total intensity across the survey were $11.27^{\circ},-2.31^{\circ}$ and $32,892 \mathrm{nT}$ respectively. The geomagnetic gradient was removed from the data using International Geomagnetic Reference Field (IGRF, 2009).

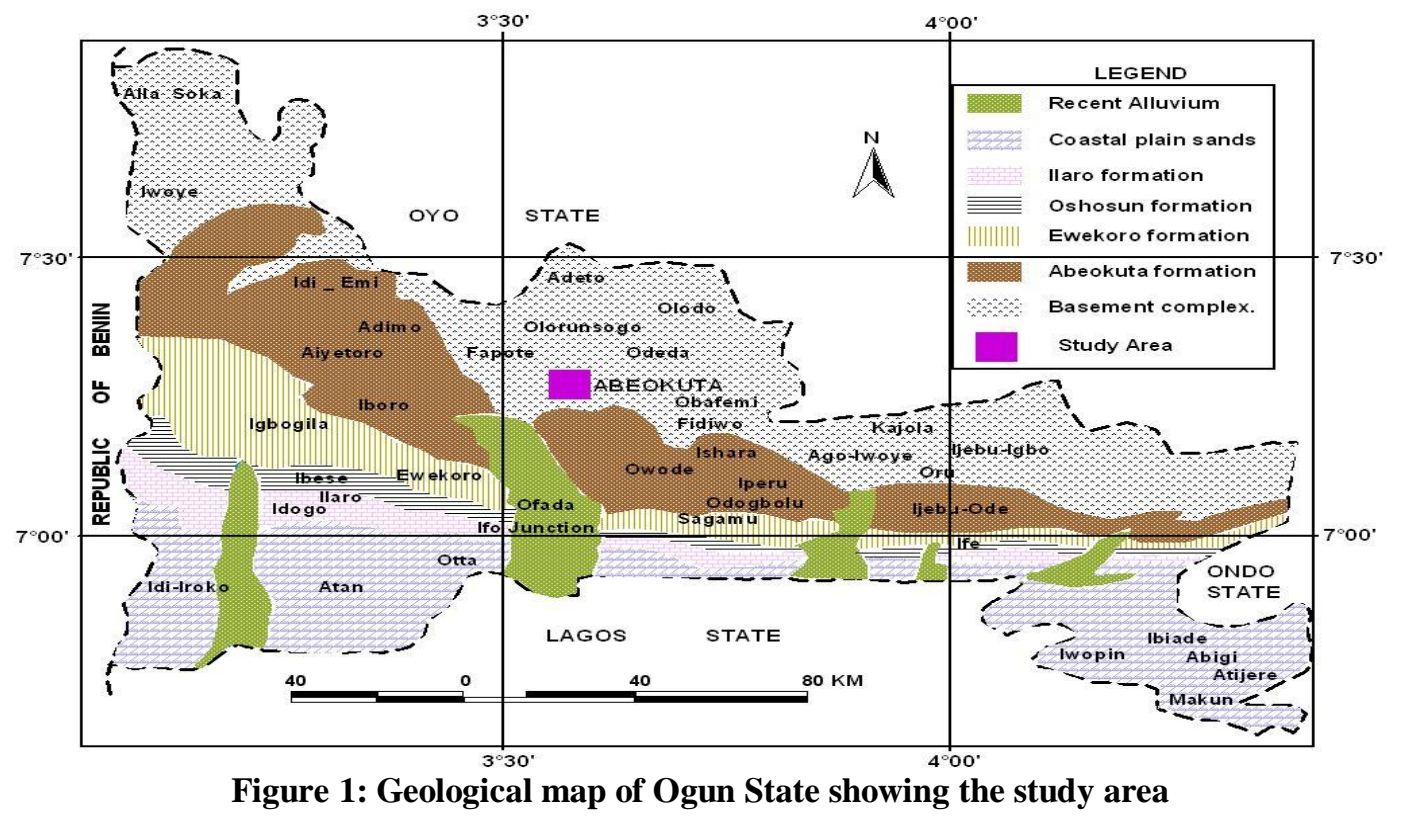

III. Methodology

In this study, we analyse estimated depth derived using the Local wavenumber. The phase angle is defined as the angle between the vertical derivative and the absolute value of the total horizontal derivative of the potential field data, which in edge detection context is termed Tilt angle (TA). The determination of the local phase (LP) and Local wavenumber (LW) for grid based data have been made easier using the methods reported by [6] and [7]. The local frequency was defined as the rate of change of the local phase (LP) with respect to $\mathrm{x}[8]$. Thus $\mathrm{f}$ can be expressed mathematically as

$f=\frac{1}{2 \pi} \frac{\partial}{\partial x} \tan ^{-1}\left[\frac{\frac{\partial M}{\partial z}}{\frac{\partial M}{\partial x}}\right]$

Defining the local wavenumber in terms of frequency

$k=2 \pi f$

Substituting Equation 1 into Equation 2 we get 
$k=\frac{1}{|A|^{2}}\left(\frac{\partial^{2} M}{\partial x \partial z} \frac{\partial M}{\partial x}-\frac{\partial M}{\partial x^{2}} \frac{\partial M}{d z}\right)$

Equation 3 is the expansion of the local wavenumber for the profile data [2]. Note that M must be differentiable at least up to order two.

For gridded data it has been shown by [9] that the wavenumber is given by

$$
\begin{aligned}
& k=\frac{1}{M_{x}^{2}+M_{y}^{2}+M_{z}^{2}} \times\left\{M_{x}\left[M_{x x}-\frac{M_{z}}{M_{x}^{2}+M_{y}^{2}}\left(M_{x} \cdot M_{x x}+M_{y} \cdot M_{x y}\right)\right]\right. \\
& \left.+M_{y}\left[M_{x y}-\frac{M_{z}}{M_{x}^{2}+M_{y}^{2}}\left(M_{x} * M_{x y}+M_{y} * M_{y y}\right)\right]\right\}
\end{aligned}
$$

By considering a sloping contact, the expressions for the vertical and horizontal gradients as defined by [10] are given by

$$
\begin{aligned}
& \frac{\partial M}{\partial z}-2 K F c \sin d \frac{x \cos (2 I-d-90)-h \sin (2 I-d-90)}{h^{2}+x^{2}} \\
& \frac{\partial M}{\partial x}-2 K F c \sin d \frac{h \cos (2 I-d-90)-x \sin (2 I-d-90)}{h^{2}+x^{2}}
\end{aligned}
$$

Where $\mathrm{K}$ is the susceptibility contrast, $\mathrm{F}$ is the magnitude of the ambient field,

$c=1-\cos ^{2} I \sin ^{2} \alpha . \quad \alpha$ is the ambient field declination, $\mathrm{I}$ is the inclination of the ambient field, $\mathrm{d}$ is the angle of dip of the body and $\mathrm{h}$ is the depth to the top of the contact.

Substituting Equation 5 and Equation 6 into Equation 4 gives

$k=\frac{h}{h^{2}+x^{2}}$

If it is assumed that the peaks coincide with the edges of the bodies, and letting $x=0$, then local depth can be written as

$h=\frac{1}{k}$

Equation 8 is the expression used to calculate the local depth from local wavenumber over maxima for the profile.

\section{Source Locations and Depths:}

\section{Results and Discussion}

The variation in the magnitude of the earth's magnetic field is shown in (Fig. 2) is to detect local changes in the properties of the underlying geology and also show that there is sizeable quantity of different magnetic deposit structures on the location.

Fig.2 shows the general magnetic susceptibility of the basement rocks and the inheritance variation. The Northeastern and North western part of the study area indicate a higher concentration of magnetically susceptible mineral (principally magnetite). Also, the south western parts of the area under consideration are dominated with broad magnetic lows (low magnetic concentration) and therefore lower susceptibility. Magnetic response is measured in nano Tesla. The range of values is from a low of $-11.0 \mathrm{nT}$ to a high of $102.7 \mathrm{nT}$. Fig. 3 is the shaded relief, which revealed the geological structure of the area under consideration and indicates heavy presence of magnetic anomaly in Abeokuta region. Horizontal Gradient technique and Local wavenumber method (also known as Source Parameter Image method) were used on the gridded data of the area under consideration. The derivative maps of (horizontal gradient and local wavenumber) are shown in the figures (4 and 5) respectively. Crests of the derivative maps (in white) correspond to the estimated source locations. On the other hand, the contact locations and depths resulting from the fore mentioned method is shown in Fig.6. Fig. 7 shows the Local phase (Tilt derivative) which ranges from -1.3rad to $1.4 \mathrm{rad}$.

From the results obtained using Local wavenumber method, it showed that the estimated depth ranges from $0.145 \mathrm{~km}$ to $2.692 \mathrm{~km}$. The result also revealed that the limit to shallow source depth is $0.145 \mathrm{~km}$ and limit to deep source depth is $2.692 \mathrm{~km}$.

The inspection of the maps elucidates the shallow depths at the northeast and southwest part of the study area. However, the deepest depths are located at the southwest part of the area (blue). 


\section{Conclusion}

In this study we present Local wavenumber method for the interpretation of digitised aeromagnetic data based on derivatives of the tilt angle. The method yields location and depth of magnetic sources without a priori information about the nature of the sources structural index. The results of this local wavenumber show clearly the variation along profiles in the surface of magnetic basement across the study area. The limit depth of the deep sources is $2.692 \mathrm{~km}$ and is believed to correspond to the surface of the magnetic basement in the study area. The shallow depth limit ranging from $0.165 \mathrm{~km}$ may refer to some major magnetic units, uplifted basement surface as well as to some local magnetic features. These results therefore demonstrate the applicability of the Local wavenumber method of magnetic interpretation in estimating source location and depths to the surface of magnetic basement in a basement complex.

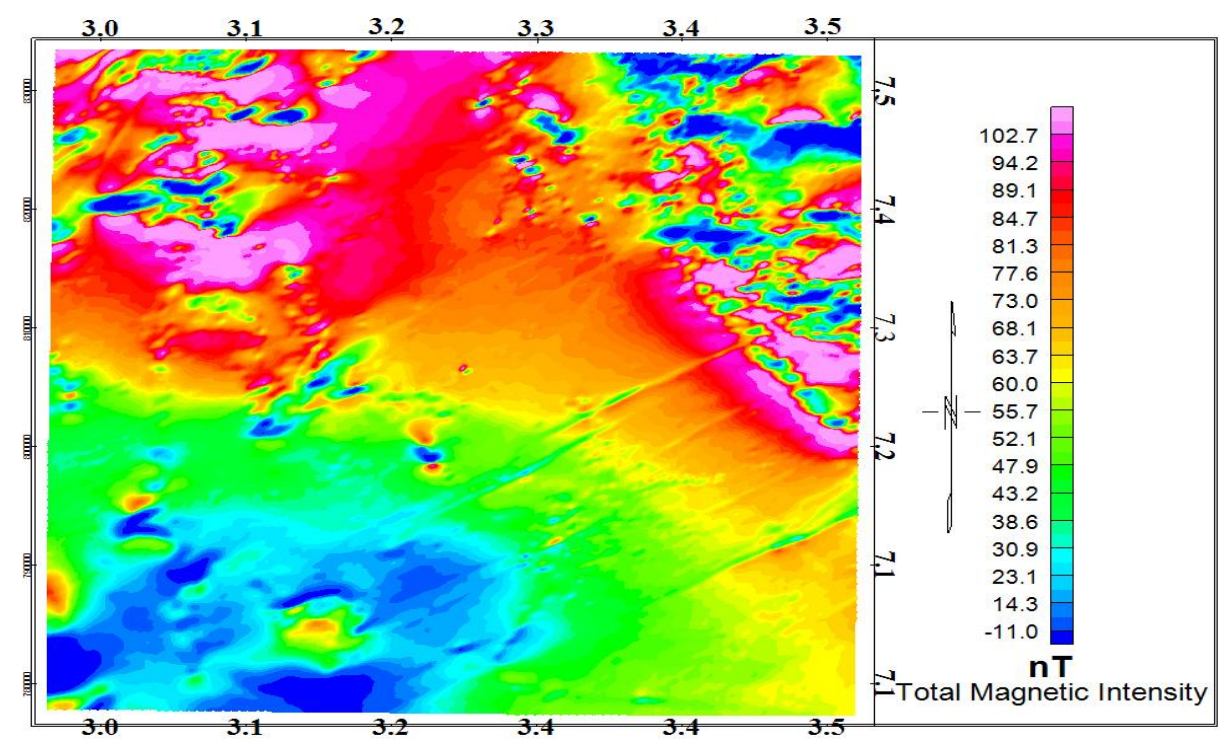

Fig.2: Total intensity magnetic map of the study area

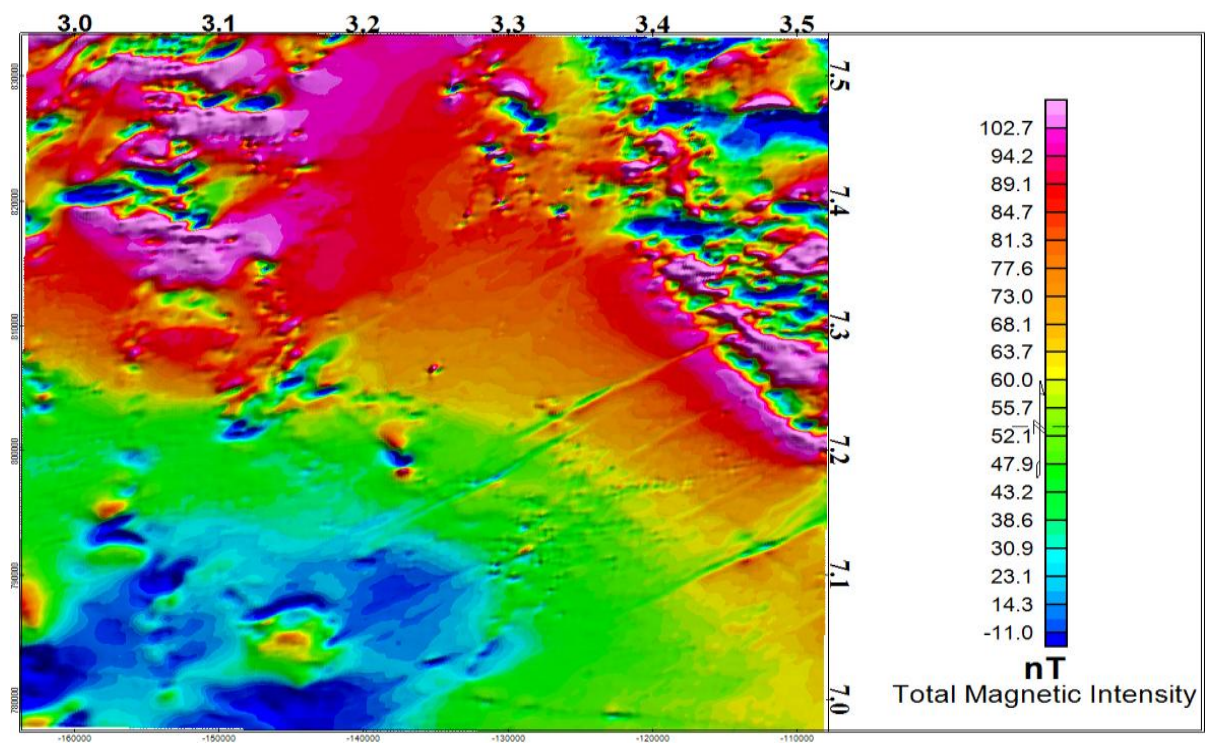

Fig.3: Shaded relief map of Abeokuta area. 


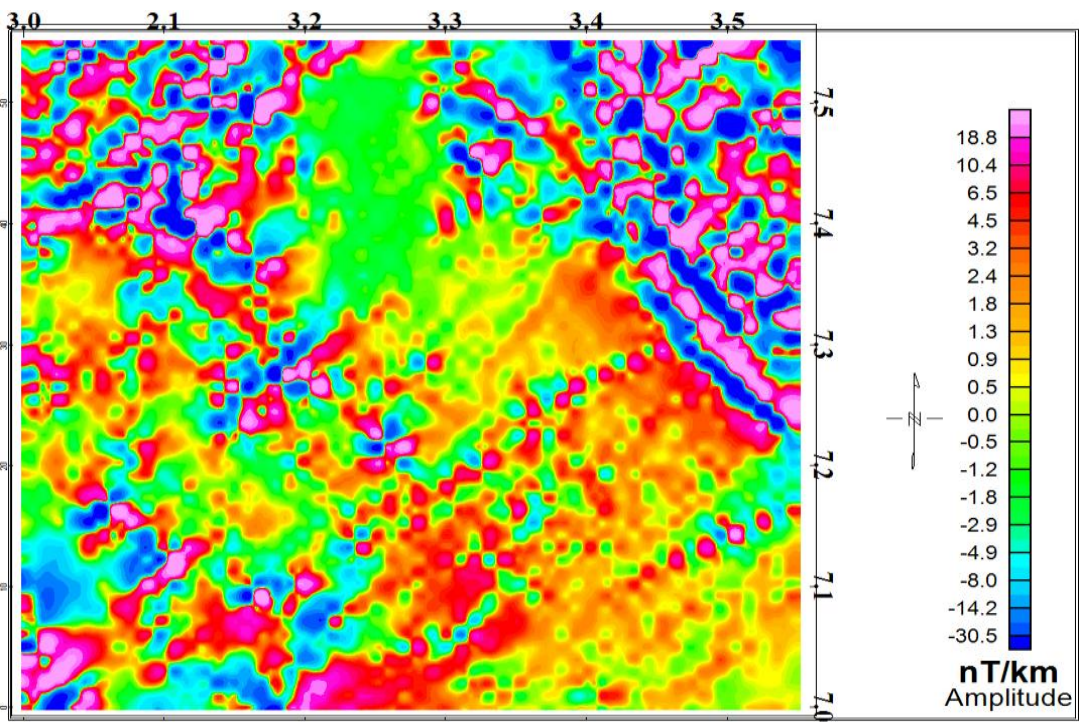

Fig.4: Horizontal gradient map of the RTP magnetic field

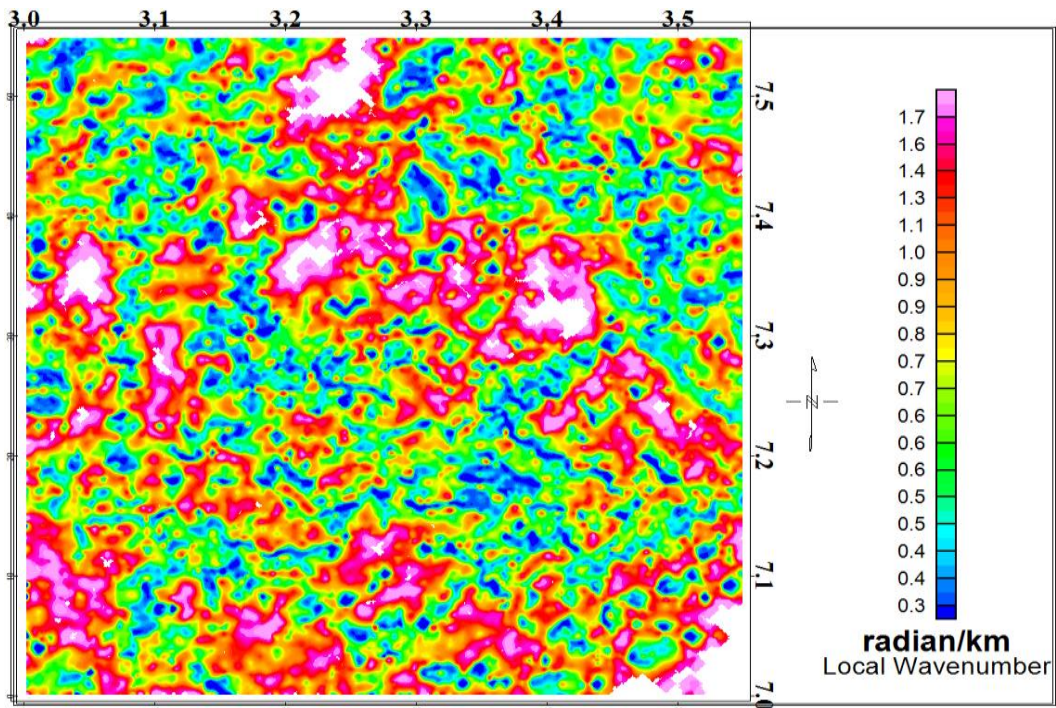

Fig. 5: Local wavenumber of the RTP Map

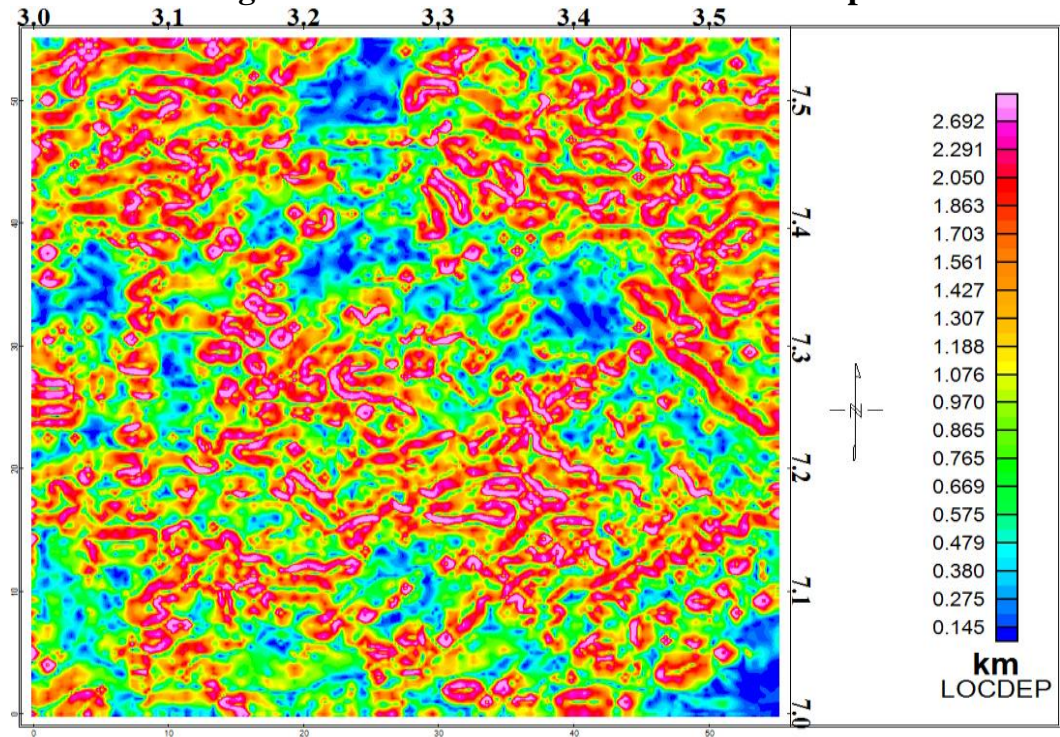

Fig.6: Sources depth as estimated by local wavenumber method 


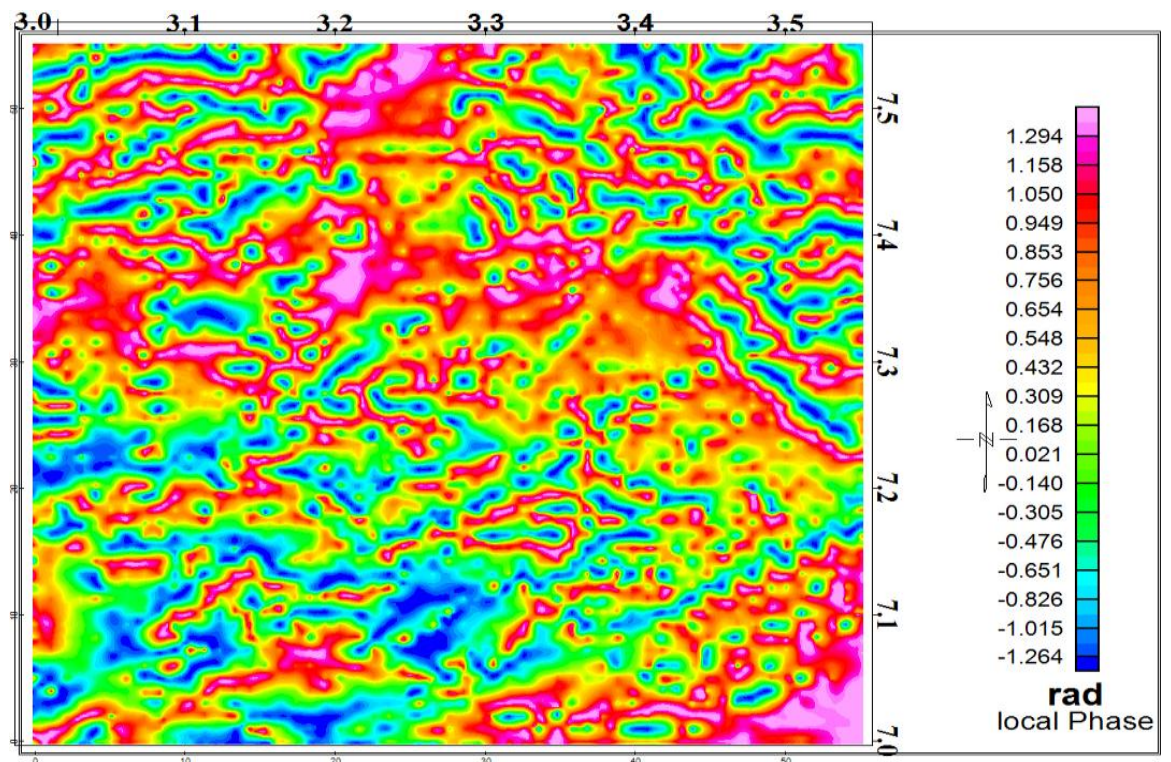

Fig.7 Local phase map of the study area

\section{References}

[1] McIntyre, J. I., 1980. Geologic significance of magnetic patterns related to magnetite in sediments and metasediments, A review, Bull. Aust. Soc. Expl. Geoph., Vol.11, pp19-33.

[2] Thurston, J. B. \& Smith, R. S. 1997. Automatic conversion of magnetic data to depth, dip, and susceptibility contrast using the SPI method. Geophysics, Vol. 62, pp. 807-813.

[3] Baranov, V. (1957). A new method for interpretation of aeromagnetic maps: pseudo-ravimetric anomalies. Geophysics, Vol. 22, pp 359-383.

[4] Obaje, N.G. (2009). Geology and mineral resources of Nigeria. Lecture Note in Earth Science Series Vol. 120

[5] Miller, H. G. \& Singh, V. (1994). Potential field tilt- A new concept for location of potential field sources. Journal of Applied Geophysics, Vol. 32, pp. 213-217

[6] Fairhead, J.D., Green, C.M., Verduzco, B., and MacKenzie, C., 2004. A new set of magnetic field derivatives for mapping minerals prospects. ASEG $17^{\text {th }}$ Geophys. Conf. and Exhibit., Syndey 2004., Extended Abstract

[7] Verduzco, B., J.D. Fairhead, C. M. Green, and C. MacKenzie, 2004. New insights into magnetic derivatives for structural mapping: The Leading Edge, Vol.23,pp 116-119.

[8] Bracewell, R., 1965, The Fourier transform and its applications: McGraw - Hill Book Co.

[9] Huang, D. and Versnel, P.A., 2000. Depth estimation algorithm applied to FTG data. Soc. Expl. Geophys. Expanded Abstract, 394 397

[10] Nabighian, M. N., 1972. The analytic signal of two dimensional magnetic bodies with polygonal cross-section: Its properties and use for automated anomaly interpretation: Geophysics, Vol.37, pp 507-517. 